\title{
An Overview of the Mitraclip Procedure Indications, Procedural Characteristics, and Clinical Outcomes
}

\author{
Rahul P. Sharma, MD*, Moody Makar, MD, Saibal Kar, MD \\ Cedars Sinai Heart Institute, Los Angeles, California, USA
}

\begin{abstract}
The MitraClip procedure is a safe and effective approach to reduction of mitral regurgitation (MR) with proven durability and clinical improvement. Procedural success is dependent on patient selection, understanding of mitral valve anatomy, particularly from an echocardiographic perspective, and attention to critical elements of the implantation such as trans septal puncture.

In the United States, the FDA has approved the MitraClip device for treatment of high risk patients with primary MR. The question of long term, sustained reduction of MR and persistent clinical improvement remains to be addressed with longer duration of follow up. Based on the impeccable safety profile of the procedure and demonstrated medium term clinical durability, future studies should be aimed at the evaluation of MitraClip for treatment of patients with severe MR deemed moderate, or indeed low risk, for surgery.

Copyright $\odot 2015$ Science International Corp.
\end{abstract}

\section{Key Words}

MitraClip • Mitral • Regurgitation • Valve

\section{Anatomical Considerations}

An understanding and appreciation of the complex anatomy of the mitral valve (MV) apparatus is imperative to achieving procedural success with the MitraClip (Abbott Vascular, Santa Clara, California, USA) device.

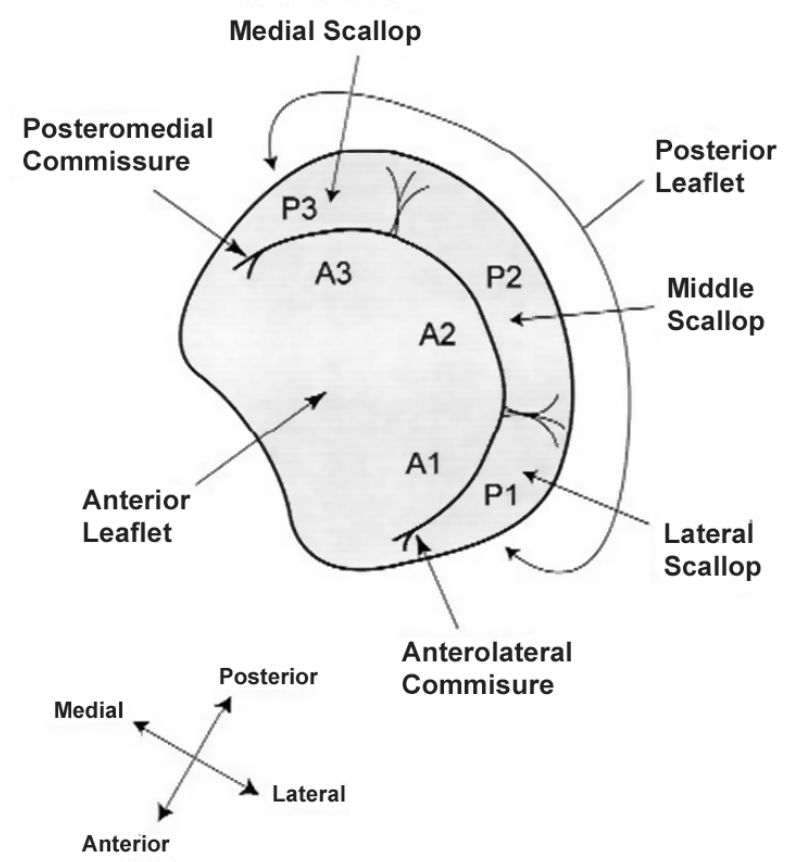

Figure 1: Mitral anatomy

The MV apparatus comprises the mitral valve, the annulus, annular attachment at the atrio-ventricular junction, tendinous chords, and the papillary muscles. The valve is made up of two leaflets, commonly referred to as the anterior and posterior leaflets (occasionally referred to as the mural and aortic leaflets, respectively). The posterior leaflet is narrow compared to the anterior leaflet and extends two-thirds around the left atrio-ventricular junction within the inlet por-

* Corresponding Author:

Saibal Kar, MD

Cardiovascular Intervention Center Research

Cedars-Sinai Medical Center

Heart Institute, Los Angeles 90048, USA

Tel.: +1 310423 3977, Fax: +1 310423 0106, Email: Saibal.Kar2@cshs.org 


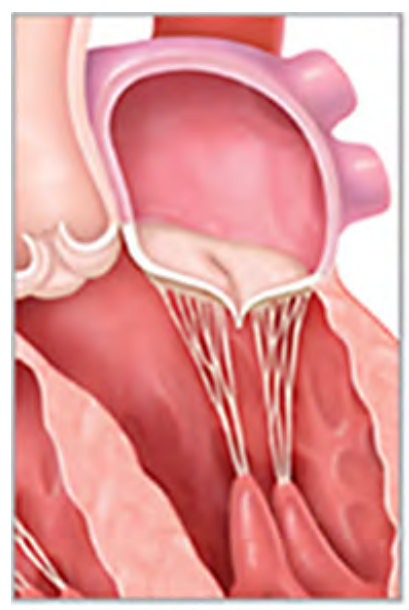

๑2012 Abbott. All rights reserved.

Figure 2: Primary MR vs FMR

tion of the ventricle. The leaflet has two clefts that separate the leaflet into three scallops along the free edge of the leaflet. The generally accepted nomenclature describes the most lateral scallop as P1, adjacent to the anterolateral commissure, the central scallop as P2, and the most medial as P3, which lies adjacent to the posteromedial commissure [1]. The semicircular anterior leaflet of the MV is broader than the anterior leaflet and comprises one-third of the annular circumference. The anterior leaflet shares a fibrous continuity with the left and non-coronary cusps of the aortic valve and between the aortic cusps abutting the membranous septum. The anterior leaflet is also divided into three regions, namely $A 1, A 2$, and $A 3$ corresponding to the opposing scallops of the posterior leaflet (Figure 1). Anatomically, the most suitable pathology for MitraClip is that involving the A2/P2 leaflets. Commisural regurgitant jets pose a technical challenge, due to difficulty delivering the clip and grasping tissue at the ends of the free edge of each leaflet. Ensuring adequate insertion of both leaflets into the clip with grasp of sufficient tissue is essential to ensure division of the mitral orifice into smaller orifices with subsequent reduction in MR. Indeed, the primary purpose of the MitraClip procedure is to perform a percutaneous edge-to-edge repair and effectively create a double mitral orifice, based on the original surgical approach to MR described by Alfieri and colleagues [2].
The mitral annulus gives a point of attachment for the mitral valve and separates the left atrium from the left ventricle. The anterior aspect of the annulus is fibrous and less prone to dilatation. The remaining posterior aspect of the annulus is muscular and therefore often subject to dilatation and calcification. The annulus is a dynamic, non-rigid, oval shaped structure that alters shape throughout the cardiac cycle. This is an important consideration during the grasping process, which should be performed slowly to ensure capture of both leaflets.

The chordae tendinae are fan-shaped chords arising from the papillary muscles (PM) and inserting into the mitral leaflets. The posteromedial PM gives chords to the medial aspect of both leaflets while the anterolateral PM chords attach to the lateral aspect of the leaflets. The anterolateral and posteromedial PM arise from the mid to apical segments of the left ventricle at the anterolateral and posterior walls respectively. Awareness of the chordal structures is important when the clip passes below the valve, as entanglement may occur. This is of greater risk when more than one clip is used, as additional clips are passed through the mitral valve in a closed position and opened below the valve, in the left ventricle.

\section{Pathophysiology}

Mitral regurgitation is the passage of blood from the left ventricle back into the left atrium during ven- 
tricular systole, occurring as a result of failure of the mitral leaflets to undergo complete coaptation (failure of leaflet tips to meet) or apposition (failure of the leaflets to overlap sufficiently). A simple classification system divides the etiology of mitral valve disease into either primary or functional (secondary) (Figure 2). Classification of MR has relevant implications for therapeutic intervention. In primary MR, the standard treatment is repair or replacement of the affected valve. In functional MR, therapy involves management of the underlying left ventricular dysfunction. For select patients in whom medical therapy is optimized, there may be a role for surgical correction.

The most common cause of primary MR is degenerative disease involving morphological changes to the valve due to thickening and stretching of leaflet tissue. The severity of these changes can range from involvement of a single scallop to both leaflets in their entirety. Fibroelastic deficiency describes a prolapsing segment, which is often normal in appearance. The prolapse is due to focal chordal elongation with or without rupture. Barlow's disease refers to myxomatous changes to both leaflets, more commonly affecting the posterior leaflet, associated with chordal thinning and elongation. Accordingly, segments of both leaflets prolapse into the left atrium. A more severe manifestation is a flail leaflet, characterized by complete eversion of the leaflet edge into the left atrium. A flail may be present in the event of primary chordal rupture and is often associated with severe mitral regurgitation. Other less common causes of primary mitral valve disease include infective endocarditis, congenital mitral cleft, and rheumatic mitral disease. The latter results in mitral stenosis with characteristic commissural fusion, with thickening and rigidity of the leaflets, eventually leading to regurgitation.

Functional MR occurs in the context of morphologically normal leaflets on a background of an underlying idiopathic cardiomyopathy or coronary artery disease. The regurgitation is due to geometric alterations of the left ventricle, which may or may not be associated with dilatation. Regional or generalized wall motion abnormalities of the left ventricle can alter the position of the papillary muscles during systole, resulting in chordal tension and leaflet restriction. Ventricular dilatation causes subsequent annular

Sharma, R.A. et al. dilatation, resulting in failure of leaflet coaptation or inadequate apposition.

\section{Clinical Outcomes and Procedural Indications}

The clinical course of MR is usually slow and progressive, except for the rare circumstance of acute MR due to papillary muscle rupture in the setting of an acute myocardial infarction. The insidious nature of the disease is a result of the ability of the heart to compensate for increasing regurgitant volume, initially through enlargement of the left atrium. As the regurgitation becomes severe, the left ventricle is subject to overload, dilatation, dysfunction, and eventual failure. The presence of left ventricular dilatation and systolic dysfunction, particularly in the context of symptomatic functional impairment, heralds a very poor prognosis if left untreated. Annual mortality rates with medical treatment in patients aged 50 years or older are approximately $3 \%$ for moderate regurgitation and approximately $6 \%$ for severe regurgitation $[3,4]$. Until recently, surgical valve repair or replacement was the only treatment proven to improve symptoms and prevent heart failure. Valve repair improves outcome compared with valve replacement and reduces mortality of patient with severe organic mitral regurgitation by about $70 \%$. As expected, the best results are obtained in asymptomatic patients operated on in advanced repair centers with low operative mortality $(<1 \%)$ and high repair rates (>80\%) [5]. These results highlight the importance of early detection, assessment and management of mitral regurgitation.

Current AHA/ACC and ESC guidelines recommend surgical intervention, preferably repair, in symptomatic patients with chronic severe primary MR and in asymptomatic patients with chronic severe primary MR with evidence of systolic dysfunction or left ventricular dilatation $[6,7]$.

For patients with secondary MR, surgical intervention carries a higher rate of operative mortality compared to that for primary MR, largely due to the severe comorbidities of these patients. As such, the AHA and ESC guidelines suggest surgery for patients with severe secondary $M R$ and preserved systolic function only when undergoing CABG or AVR $[6,7]$.

While surgery remains the gold standard of treatment, there are patients who are either at prohibi- 
Table 1: Summary of MitraClip studies

\begin{tabular}{|c|c|c|c|c|c|c|c|c|c|c|}
\hline Study & $\begin{array}{l}\text { No. of } \\
\text { Patients }\end{array}$ & $\begin{array}{l}\text { Etiology } \\
\text { of MR }\end{array}$ & Age & STS Score & EuroScore & $M R \leq 2+\%$ & $\begin{array}{l}30-d \\
\text { Mortality \% }\end{array}$ & $\begin{array}{l}\text { 1-yr } \\
\text { Mortality \% }\end{array}$ & $\begin{array}{l}M R \geq 3+ \\
\text { at } 1 \mathrm{yr}\end{array}$ & $\begin{array}{l}\text { Need for } \\
\text { Surgery }\end{array}$ \\
\hline $\begin{array}{l}\text { Franzen } \\
\text { et al. }\end{array}$ & 51 & $\begin{array}{l}\text { DMR 31\% } \\
\text { FMR 69\% }\end{array}$ & $73 \pm 10$ & $15 \pm 11$ & $29 \pm 22$ & 94 & 2 & $\mathrm{n} / \mathrm{a}$ & $\mathrm{n} / \mathrm{a}$ & $\mathrm{n} / \mathrm{a}$ \\
\hline $\begin{array}{l}\text { Tamburino } \\
\text { et al. }\end{array}$ & 31 & $\begin{array}{l}\text { DMR 42\% } \\
\text { FMR 58\% }\end{array}$ & $\begin{array}{l}71 \\
(62-79)\end{array}$ & $10 \pm 9$ & $14 \pm 12$ & 97 & 3.2 & $\mathrm{n} / \mathrm{a}$ & $\mathrm{n} / \mathrm{a}$ & $\mathrm{n} / \mathrm{a}$ \\
\hline $\begin{array}{l}\text { PERMIT- } \\
\text { CARE }\end{array}$ & 51 & FMR & $70 \pm 9$ & $14 \pm 14$ & $30 \pm 19$ & 82 & 4.2 & 18 & $\mathrm{n} / \mathrm{a}$ & $\mathrm{n} / \mathrm{a}$ \\
\hline $\begin{array}{l}\text { Rudolph } \\
\text { et al. }\end{array}$ & 104 & $\begin{array}{l}\text { DMR 34\% } \\
\text { FMR 66\% }\end{array}$ & $74 \pm 9$ & $\mathrm{n} / \mathrm{a}$ & $36(21-54)$ & 94 & 3.8 & 25 & 18 & 6.7 \\
\hline TRAMI & 470 & $\begin{array}{l}\text { DMR 33\% } \\
\text { FMR 67\% }\end{array}$ & $75 \pm 5$ & 11 (4-19) & $23(12-38)$ & 94 & 2.5 & $\mathrm{n} / \mathrm{a}$ & $\mathrm{n} / \mathrm{a}$ & $\mathrm{n} / \mathrm{a}$ \\
\hline EVEREST I & 107 & $\begin{array}{l}\text { DMR 79\% } \\
\text { FMR } 21 \%\end{array}$ & $\begin{array}{l}71 \\
(26-88)\end{array}$ & $\mathrm{n} / \mathrm{a}$ & $\mathrm{n} / \mathrm{a}$ & 74 & 0.9 & 4.1 & $\mathrm{n} / \mathrm{a}$ & 29.9 \\
\hline $\begin{array}{l}\text { EVEREST } \\
\text { High risk } \\
\text { registry }\end{array}$ & 78 & $\begin{array}{l}\text { DMR 41\% } \\
\text { FMR 59\% }\end{array}$ & $77 \pm 10$ & $14 \pm 8$ & $n / a$ & 80 & 7.7 & 24.4 & 20 & 0 \\
\hline $\begin{array}{l}\text { ACCESS- } \\
\text { EUROPE }\end{array}$ & 567 & $\begin{array}{l}\text { DMR 23\% } \\
\text { FMR 77\% }\end{array}$ & $74 \pm 10$ & $\mathrm{n} / \mathrm{a}$ & $23 \pm 18$ & 79 & 3.4 & 17.3 & 21 & 6.3 \\
\hline EVEREST II & 186 & $\begin{array}{l}\text { DMR 73\% } \\
\text { FMR } 27 \%\end{array}$ & $67 \pm 13$ & $5 \pm 4$ & $\mathrm{n} / \mathrm{a}$ & 78 & 1 & 6 & 22 & 20 \\
\hline $\begin{array}{l}\text { EVEREST II } \\
\text { /REALISM } \\
\text { High risk } \\
\text { registry }\end{array}$ & 351 & $\begin{array}{l}\text { DMR 30\% } \\
\text { FMR 70\% }\end{array}$ & $76 \pm 11$ & $11.3 \pm 7.7$ & $\mathrm{n} / \mathrm{a}$ & 86 & 4.8 & 22.8 & 14 & 0.3 \\
\hline $\begin{array}{l}\text { COAPT } \\
\text { (enrolling) }\end{array}$ & 430 & $F M R$ & - & - & - & - & - & - & - & - \\
\hline
\end{tabular}

tively high risk for, or do not benefit from, a surgical procedure, particularly those with functional MR. The MitraClip procedure is a novel, minimally invasive, transcatheter procedure that can be offered to such patients. To date, there have been a number of trials and registry studies examining the safety and efficacy of the MitraClip device when compared to standard medical therapy and to surgery.

The results of the relevant clinical studies are summarized in Table 1 [8-15]. In all of these studies, procedural success was achieved in the majority of patients with reduction of MR from 4+ to less than $2+$. Furthermore, these results were generally achieved with an excellent safety profile without any significant rate of adverse procedural outcomes.

The EVEREST cohort is a prospective multicenter registry that analyzed the feasibility, safety and efficacy of MitraClip in patients with moderate-to-severe
(3+) or severe (4+) MR with class I surgical indication. A total of 107 patients were enrolled (55 from EVEREST I and 52 in the prerandomization phase of EVEREST II), with a mean follow-up of almost 2 years. The EVEREST cohort established that the MitraClip procedure is safe, with a low periprocedural complication rate. In carefully selected patients, it has acceptable efficacy achieving significant MR reduction in more than two-thirds of patients [13].

The landmark study was Everest II, a multicenter randomized clinical trial designed to compare the efficacy and safety of percutaneous treatment with MitraClip vs. conventional repair surgery or MV replacement. Compared to surgery, at 1 year, MitraClip was less effective than surgical repair due to the increased prevalence of residual MR compared to surgery. However, the clip reduced severity of MR, improved symptoms, and led to reverse LV remodeling [16]. The improve- 


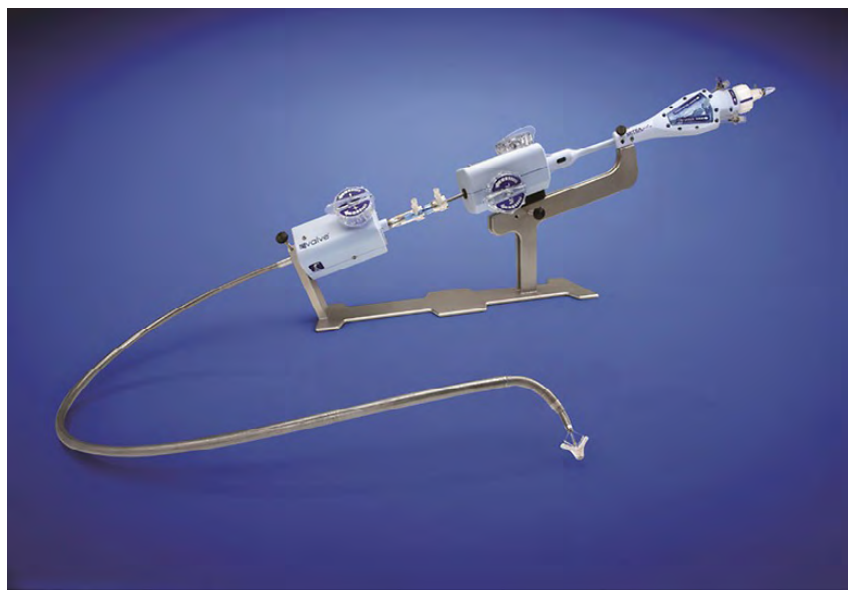

Figure 3: MitraClip device

ment in NYHA functional class at 1 year was sustained at 4 years. The 4-year results demonstrated no mortality difference between the two groups, a low rate of MV surgery in the percutaneous repair group beyond the first 6 months of therapy, and a low rate of adverse events from 1 to 4 years in both groups [17].

The EVEREST II high-risk registry (HRR) included patients with moderate-severe or severe MR with an estimated surgical risk of $12 \%$ or greater (based on the Society of Thoracic Surgeons risk score or as estimated by the surgical team). Enrolment of patients has continued as part of the REALISM registry which has two arms: 1 with high-risk patients and the other with non-high risk patients, The combined REALSIM and EVEREST II High Risk Registry demonstrated an impressive 30 day mortality of less than $5 \%$ with significant improvement in symptom status, reduced rate of hospitalization and improved left ventricular remodeling at one year [15].

Based on the outcomes from Everest II the AHA/ ACC guidelines state that the MitraClip should only be considered for patients with chronic primary MR who remain severely symptomatic with NYHA class III to IV HF symptoms despite optimal heart failure therapy and who are considered inoperable [6].

The ESC guidelines recommend that MitraClip may be considered in patients with symptomatic severe primary MR who fulfill the echo criteria of eligibility, are judged inoperable or at high surgical risk by a 'heart team,' and have a life expectancy greater than 1 year [7].

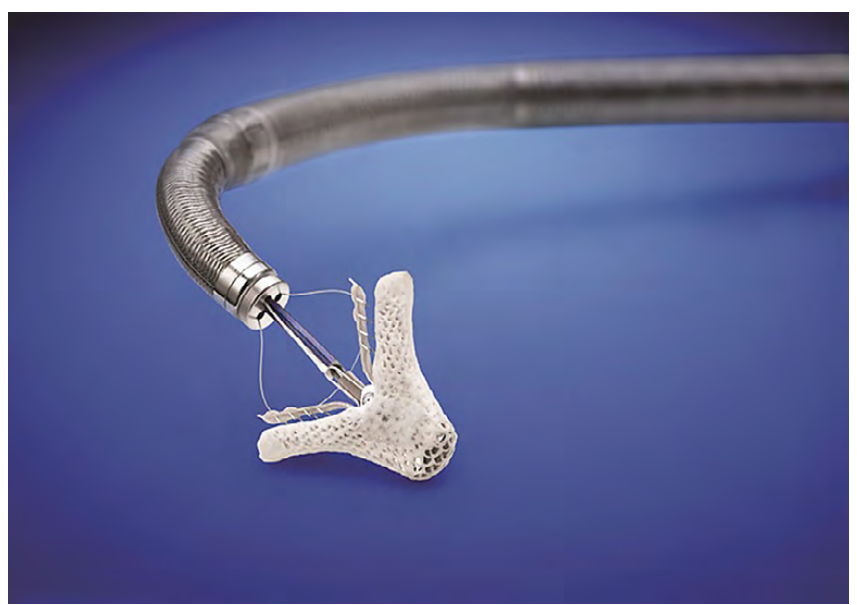

Figure 4: Clip

Furthermore, based on experience the EVEREST trials and from observational studies, ESC guidelines suggest that MitraClip is feasible at low procedural risk in patients with secondary MR in the absence of severe tethering and may provide short-term improvement in functional condition and LV function [7].

While the AHA/ACC guidelines acknowledge that MitraClip provides a less invasive alternative to surgery, it is noted that the procedure is not yet approved for clinical use in the United States [6].

The COAPT trial is a currently enrolling, randomized, parallel-controlled, multicenter clinical evaluation of the MitraClip device for the treatment of clinically significant functional mitral regurgitation in symptomatic heart failure subjects who are treated per standard of care and who have been deemed ineligible for mitral valve surgery. Eligible subjects will be randomized in a 1:1 ratio to the MitraClip device or to no MitraClip device (control group). The primary outcome measures include the primary safety endpoint (composite of single leaflet device attachment, device embolizations, endocarditis requiring surgery, mitral stenosis requiring surgery, and any device related complications requiring non-elective cardiovascular surgery) and the primary effectiveness (recurrent heart failure hospitalizations). The results of this study are eagerly anticipated to prove the efficacy of MitraClip in patients with functional MR. 


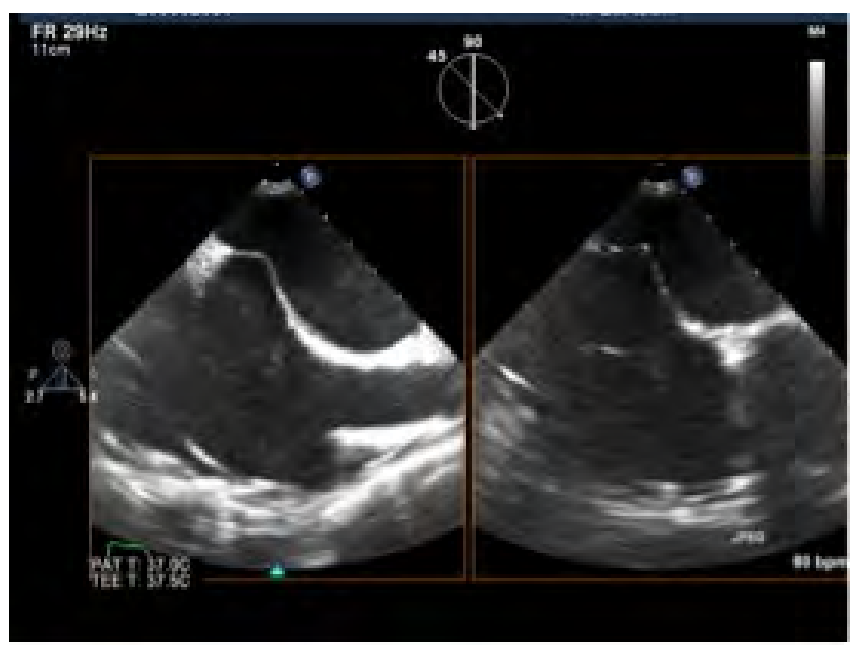

Figure 5: Trans septal puncture

\section{MitraClip Device}

The complete device apparatus consists of a steerable Guide handle attached to the steerable sleeve and the Clip Delivery System (CDS), comprising the clip itself, the Delivery Catheter Handle (DCH), and the delivery catheter (Figure 3 ). The clip consists of a 4-mm wide and 8-mm long chrome-cobalt clip with two articulated arms that open from $0^{\circ}$ (closed position) to $240^{\circ}$ (open position), allowing grasping and drawing together of the anterior and posterior leaflets. The inner parts of the arms are grippers, lined with small frictional elements that grasp the leaflets once the device has been closed. The outer part is covered in a polyester mesh to promote tissue growth and the formation of a fibrous tissue bridge between the leaflets (Figure 4). The MitraClip device is delivered using a $24 \mathrm{Fr}$ catheter guide with a mobile steerable tip to position the clip. The delivery system has two knobs that control the anterior-posterior and medial-lateral steering of the catheter tip. The DC handle comprises two levers to lock/unlock the clip and to lift/depress the gripper lines, a knob to facilitate the opening and closing of the clips and a screw to enable release of the clip from the shaft of the delivery catheter.

\section{Procedure}

The MitraClip procedure is performed under general anesthesia, primarily to enable pauses in ventilation and thereby ensure precise clip positioning.

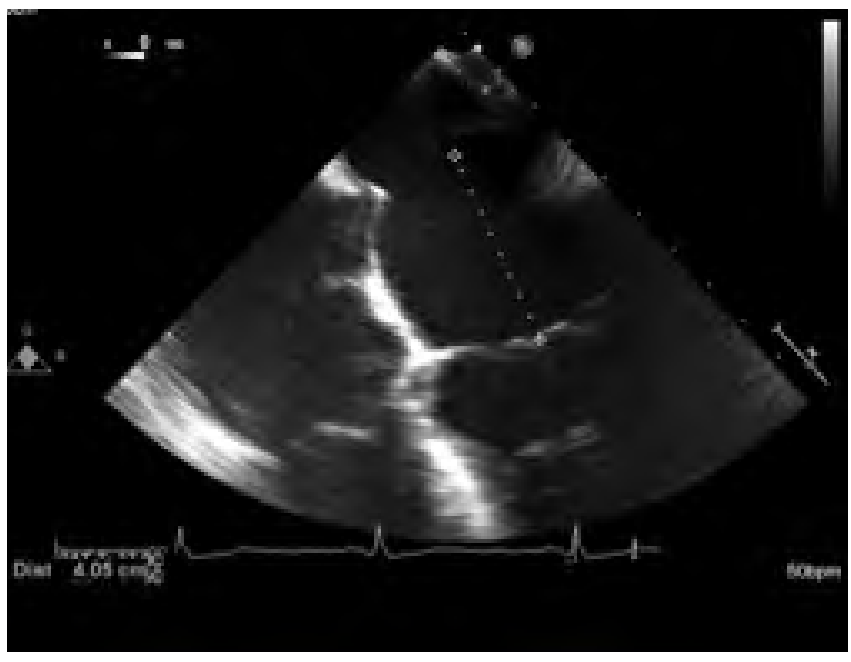

Figure 6: Device Distance

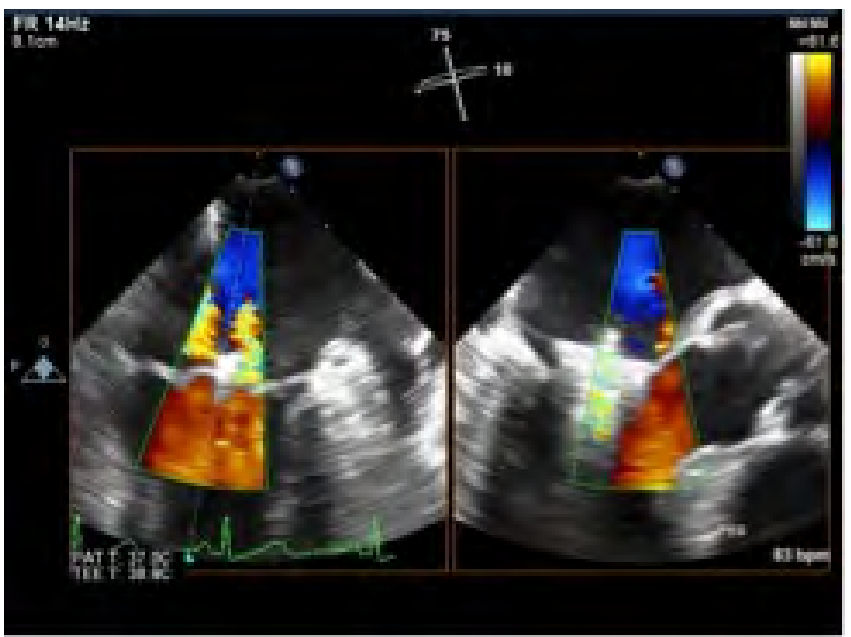

Figure 7: Bicommisural and LVOT view

The additional advantage of general anesthesia is comfort to the patient, particularly in the context of extended periods of TEE evaluation.

One of the key advantages of the MitraClip procedure is venous access. We recommend using a micropuncture needle to minimize vascular complications. The first venous access site is the jugular or femoral vein for right heart catheterization at the commencement of the procedure and immediately following release of the clip. A second venous sheath is placed in the femoral vein for eventual passage of the MitraClip apparatus. A PerClose Proglide suture can be placed in a 'pre-close' fashion to achieve hemostasis at the end of the case. 
Cardiac imaging with visualization of the interatrial septum (IAS) and the mitral valve apparatus is vital to the success of the MitraClip procedure. Operators should be well versed in obtaining and interpreting echocardiographic views to guide trans-septal puncture, device positioning and clip deployment. Furthermore, operators should be aware of the parameters used to assess the success of clip deployment based on echocardiographic interrogation. At our institution, TEE is performed by a cardiac anesthesiologist experienced in MitraClip procedures, with an understanding of the expectations and requirements of the operator. Effective communication between the individual procuring the TEE images and the operator is imperative to facilitate an efficient and effective procedure.

The trans-septal puncture is arguably the most critical step of the procedure. If the puncture is inaccurate, subsequent device maneuverability and clip positioning is made difficult, often resulting in failed, or at best, unsatisfactory clip deployment position reflected by minimal or no improvement in MR. Indeed, poor clip position may in fact worsen the degree of MR or cause MS. Accordingly, we take great care to ensure precise trans-septal puncture, repeating the process if necessary to ensure an optimal starting position. The trans-septal puncture is performed under both fluoroscopic and TEE guidance using standard equipment and technique.

We recommend simultaneous viewing of a short axis image for anteroposterior positioning and a bicaval image for superoinferior positioning. The optimal puncture site is located slightly inferior and posterior on the septum (Figure 5). Once this position is located we obtain a 0 degree, 4 chamber view to measure the "device distance", defined as the distance of the septal puncture from the mitral annulus. Ideally, this distance should be $4.0-4.5 \mathrm{~cm}$ above the mitral annulus as measured perpendicular to the plane of mitral valve coaptation during systole (Figure 6). If difficulty is encountered puncturing the septum, such as in the case of a thickened or fibrotic septum, focal cauterization of the septum can be used to facilitate entry.

Once the needle is across the septum the entire system is advanced into the left atrium and heparin is administered for anticoagulation. The 24F Abbott
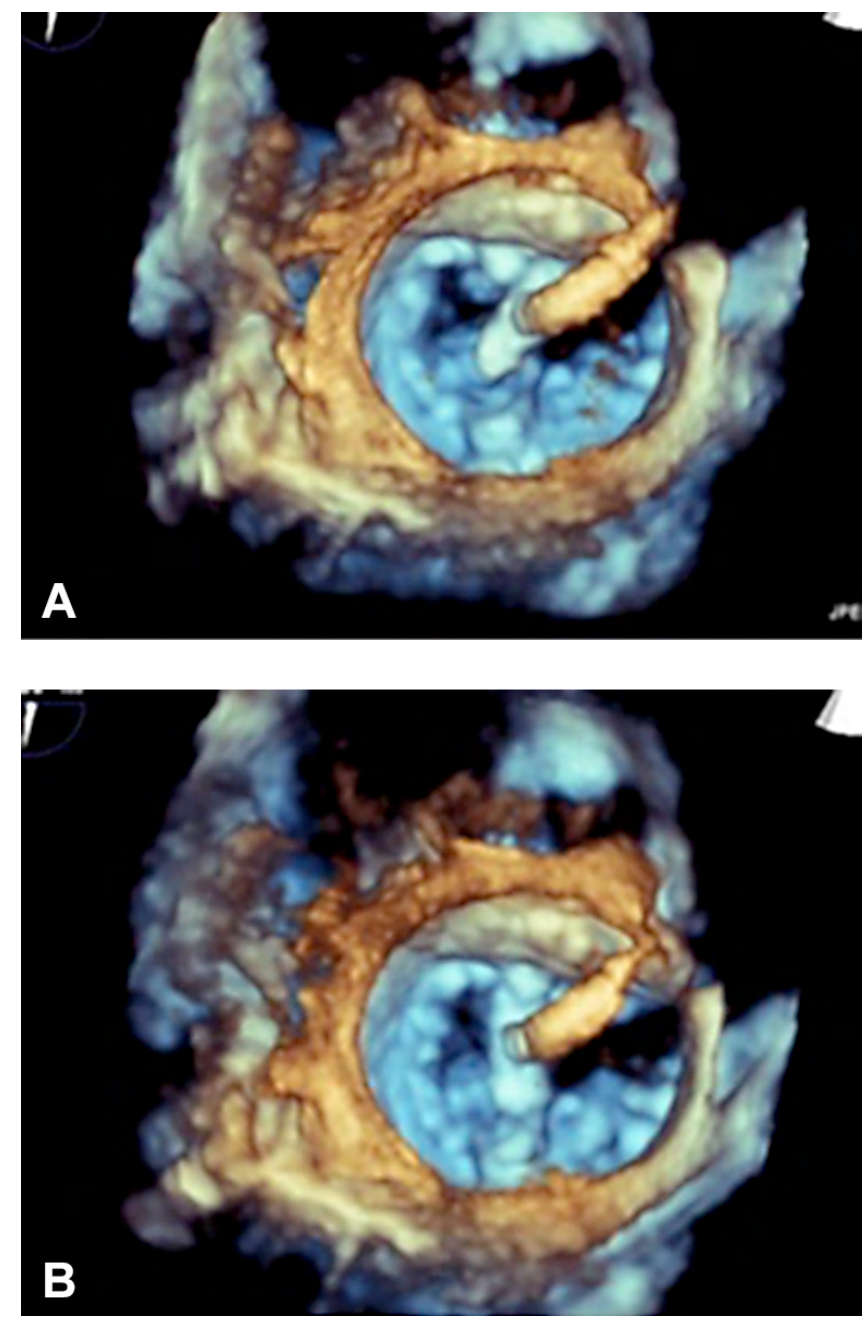

Figure 8: A. Checking orientation in 3D enface view. B. Correcting orientation in $3 \mathrm{D}$ enface view

MitraClip delivery steerable system is then advanced over a Superstiff wire into the left atrium. The Superstiff wire is then removed and baseline left atrial pressure is recorded. The MitraClip device is then carefully advanced into the left atrium through the device deployment sheath under fluoroscopy and TEE guidance.

From the plane of entry into the left atrium, parallel to the mitral annulus, the clip delivery system can be steered towards the valve using the mediolateral steering knob to turn the device 90 degrees and by turning the guide clockwise, aligning the clip perpendicular to the annulus. Once the device reaches just above the leaflets, an assessment is made of the position of the clip in a mediolateral and anteroposterior plane, using bicommissural and LV outflow tract 

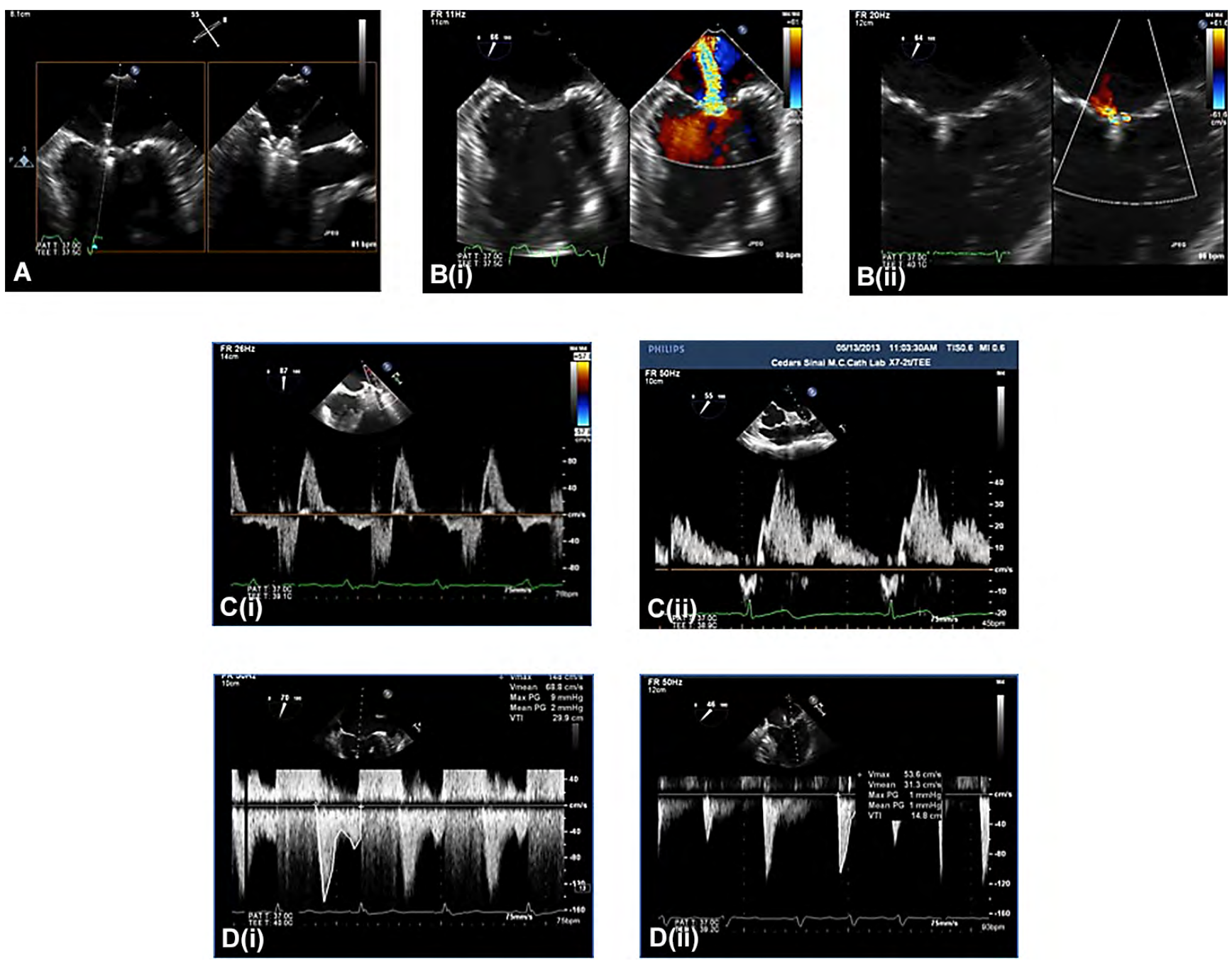

Figure 9: Pre deployment check: A. Leaflet insertion. B. Reduction in regurgitation (i) pre (ii) post. C. Pulmonary vein assessment (i) pre (ii) post. D. Mitral Stenosis (i) pre (ii) post.

echocardiographic views respectively (Figure 7). The trajectory of the clip is examined by moving the DC handle up and down while assessing the direction of the delivery shaft. Adjustments in the medial or lateral direction are made in the bi-commissural view either by moving the entire system or by adjusting the ' $M$ ' knob. Adjustments in the anterior or posterior direction are made in the LVOT view by rotating the guide handle clockwise or counter-clockwise. Once an ideal position is achieved, the clip is opened to 180 degrees and a 3-D en face surgical view of the mitral valve is obtained to assess for orientation of the clip arms relative to the leaflets (Figure 8). Any adjustments are made by rotating the DC handle in the desired direction then transmitting the torque by moving the handle up and down rapidly. Once the clip is perpendicular to the leaflets, the clip is advanced in the open position through the valve. The orientation of the clip is re-checked, the clip is closed to 120 degrees, and the DC handle retracted slowly to grasp both leaflets in the device. Once leaflet capture is confirmed the grippers are pushed down and the clip is closed. TEE interrogation is then performed in multiple views to ensure leaflet capture with adequate tissue grasp, reduction in MR (assessed by regurgitant volume, size of MR PISA and pulmonary vein Doppler), and absence of a significant gradient (Figure 9). If these procedural goals have been met, 
the clip is released. The TEE evaluation is repeated once more and if there is significant residual MR and no significant gradient $(>6 \mathrm{mmHg})$ additional clips can be deployed. These are deployed in the previously described manner with one key differencesubsequent clips are passed through the valve in a closed position and opened below the valve in the ventricle. Placement of additional clips carries a risk of worsening MR (due to deformation of the leaflets), clip interaction and potential instability, and significant stenosis. In our experience, it is technically more challenging to place additional clips medial to the first clip. As such, when reviewing echo images prior to the procedure and expecting the need for multiple clips, or if considering an additional clip during the procedure, we aim to place the first clip in the more medial position and all subsequent clips laterally. An inherent advantage of the MitraClip procedure is the ability to remove a clip following closure and subsequent assessment. Accordingly, if the operator is dissatisfied with the result of an additional clip this can simply be opened, detached from the leaflet, brought back into the guide, and removed from the body.

The MitraClip procedure is generally safe and well tolerated. Aside from the risks associated with general anesthesia, those specific to the procedure include: femoral venous complications; trans-septal trauma resulting in an atrial septal defect (significant shunts may require closure), left atrial perforation (care must be taken to manipulate the guide catheter away from the posterior wall of the left atrium prior to removal); clip detachment and embolization (clip stability must be assessed fluoroscopically and via echocardiography prior to final release of the clip); and endocarditis. The overall rate of such adverse events in our experience is less than $1 \%$.

\section{Conclusion}

The MitraClip procedure is a safe and effective approach to reduction of MR with proven durability and clinical improvement. The safety of the procedure is attributable to two key elements. Firstly, the percutaneous trans venous access, which limits the significance of vascular complications compared to an open surgical approach. Secondly, the trans septal approach, which is a far less invasive method of accessing the mitral valve compared to surgical access via the left atrium.

In the United States, the FDA has approved the MitraClip device for treatment of high risk patients with primary MR. The currently enrolling randomized COAPT study will help address the question regarding the benefit of MitraClip in conjunction with guideline directed medical therapy when compared to standard care in high risk patients with FMR. Furthermore, the question of long-term, sustained reduction of MR and persistent clinical improvement remains to be addressed with longer duration of follow up. Based on the impeccable safety profile of the procedure and demonstrated medium-term clinical durability, future studies should be aimed at the evaluation of MitraClip for treatment of patients with severe primary or functional MR deemed moderate, or indeed low risk, for surgery.

\section{Conflict of Interest}

Dr. Saibal Kar is a proctor for MitraClip.

\section{Comment on this Article or Ask a Question}

\section{References}

1. Carpentier A. Mitral valve annuloplasty. Ann Thorac Surg. 1990;49:508-509. PMID: 2310267

2. Alfieri O, Maisano F, De Bonis M, Stefano $\mathrm{PL}$, Torracca L, Oppizzi M, et al. The double-orifice technique in mitral valve repair: A simple solution for complex problems. J Thorac Cardiovasc Surg. 2001;122:674-681. PMID: 11581597

3. Ling LH, Enriquez-Sarano M, Seward JB, Tajik AJ, Schaff HV, Bailey KR, et al. Clinical out- come of mitral regurgitation due to flail leaflet. N Engl J Med. 1996;335:1417-1423. DOl: 10.1056/NEJM199611073351902

4. Enriquez-Sarano $M$, Nkomo V, Mohty $D$, Avierinos JF, Chaliki H. Mitral regurgitation: Predictors of outcome and natural history. Adv Cardiol. 2002;39:133-143. DOI: 10.1159/000058920

5. Enriquez-Sarano $M$, Akins CW, Vahanian A. Mitral regurgitation. Lancet. 2009:373:1382-1394. DOI: 10.1016/S0140-
6736(09)60692-9

6. Nishimura RA, Otto $C M$, Bonow RO, Carabello BA, Erwin JP, 3rd, Guyton RA, et al. 2014 AHA/ACC guideline for the management of patients with valvular heart disease: A report of the American College of Cardiology/American Heart Association Task Force on Practice Guidelines. J Am Coll Cardiol. 2014;63:e57-185. DOI: 10.1161/CIR.0000000000000029

7. Vahanian A, Alfieri $O$, Andreotti F, Antunes 
MJ, Baron-Esquivias G, Baumgartner $H$, et al. Guidelines on the management of valvular heart disease (version 2012): The Joint Task Force on the Management of Valvular Heart Disease of the European Society of Cardiology (ESC) and the European Association for Cardio-Thoracic Surgery (EACTS). Eur J Cardiothorac Surg. 2012;42:S1-44. DOI: 10.1093/ejcts/ezs455

8. Franzen $\mathrm{O}$, Baldus $\mathrm{S}$, Rudolph $\mathrm{V}$, Meyer $\mathrm{S}$, Knap M, Koschyk D, et al. Acute outcomes of MitraClip therapy for mitral regurgitation in high-surgical-risk patients: Emphasis on adverse valve morphology and severe left ventricular dysfunction. Eur Heart J. 2010;31:1373-1381. DOI: 10.1093/ eurheartj/ehq050

9. Tamburino C, Ussia GP, Maisano F, Capodanno D, La Canna G, Scandura S, et al. Percutaneous mitral valve repair with the MitraClip system: Acute results from a real world setting. Eur Heart J. 2010;31:1382-1389. DOI: 10.1093/eurheartj/ehq051

10. Auricchio A, Schillinger W, Meyer S, Maisano F, Hoffmann R, Ussia GP, et al. Correction of mitral regurgitation in nonresponders to cardiac resynchronization therapy by MitraClip improves symptoms and promotes reverse remodeling. J Am Coll Cardiol. 2011;58:2183-2189. DOI: 10.1016/j. jacc.2011.06.061

11. Rudolph V, Lubos $E$, Schluter $M$, Lubs $D$, Goldmann B, Knap M, et al. Aetiology of mitral regurgitation differentially affects 2-year adverse outcomes after MitraClip therapy in high-risk patients. Eur J Heart Failure. 2013;15:796-807. DOI: 10.1093/ eurjhf/hft021

12. Wiebe J, Franke J, Lubos E, Boekstegers $P$, Schillinger W, Ouarrak T, et al. Percutaneous mitral valve repair with the MitraClip system according to the predicted risk by the logistic EuroSCORE: Preliminary results from the German Transcatheter Mitral Valve Interventions (TRAMI) Registry. Catheter Cardiovasc Interv. 2014;84:591598. DOI: $10.1002 / \mathrm{ccd} .25493$

13. Feldman $T$, Kar $S$, Rinaldi $M$, Fail $P$, Hermiller J, Smalling R, et al. Percutaneous mitral repair with the MitraClip system: Safety and midterm durability in the initial EVEREST (Endovascular Valve Edgeto-Edge REpair Study) cohort. J Am Coll Cardiol. 2009;54:686-694. DOI: 10.1016/j. jacc.2009.03.077

14. Maisano F, Franzen $O$, Baldus $S$, Schafer U, Hausleiter J, Butter C, et al. Percutaneous mitral valve interventions in the real world: Early and 1-year results from the ACCESS-EU, a prospective, multicenter, nonrandomized post-approval study of the MitraClip therapy in Europe. J Am Coll Cardiol. 2013;62:1052-1061. DOI: 10.1016/j. jacc.2013.02.094

15. Glower DD, Kar S, Trento A, Lim DS, Bajwa T, Quesada $\mathrm{R}$, et al. Percutaneous mitral valve repair for mitral regurgitation in high-risk patients: results of the EVEREST II study. J Am Coll Cardiol. 2014;64:172-181. DOI: 10.1016/j.jacc.2013.12.062
16. Whitlow PL, Feldman T, Pedersen WR, Lim DS, Kipperman R, Smalling R, et al. Acute and 12-month results with catheter-based mitral valve leaflet repair: the EVEREST II (Endovascular Valve Edge-to-Edge Repair) High Risk Study. J Am Coll Cardiol. 2012;59:130-139. DOI: 10.1016/j. jacc.2011.08.067

17. Mauri L, Foster E, Glower DD, Apruzzese P, Massaro JM, Herrmann HC, et al. 4-year results of a randomized controlled trial of percutaneous repair versus surgery for mitral regurgitation. J Am Coll Cardiol. 2013;62:317-328. DOI: 10.1016/j. jacc.2013.04.030

Cite this article as: Sharma R, Makar M, Kar S. An Overview of the Mitraclip Procedure. Structural Heart Disease 2015;1(3):127-136. DOI: http://dx.doi. org/10.12945/j.jshd.2015.018-14 